Among 9 patients who were on treatment with prednisone at the start of the last IL-1 inhibitor, the prednisone median dose was $12.5 \mathrm{mg} /$ day [10.0-18.8] while at the last follow-up visit it was $5.0 \mathrm{mg} /$ day $[0-7.5](p=0.02)$.

The retention rate of IL-1 inhibitors was $73.4 \%$ [SE 9.4] at 1 year and $63.6 \%$ [SE 10.4] at 2 years (Figure 1a). There was no significant difference between the retention rate of anakinra (at 1 year: $67.0 \%$ [12.2]; at 2 years: $59.6 \%$ [12.9]) and canakinumab (at 1 year: $85.7 \%$ [13.2]; at 2 years $71.4 \%$ [17.1]) (log-rank test: $\mathrm{p}=0.41$ ) (Figure 1b).
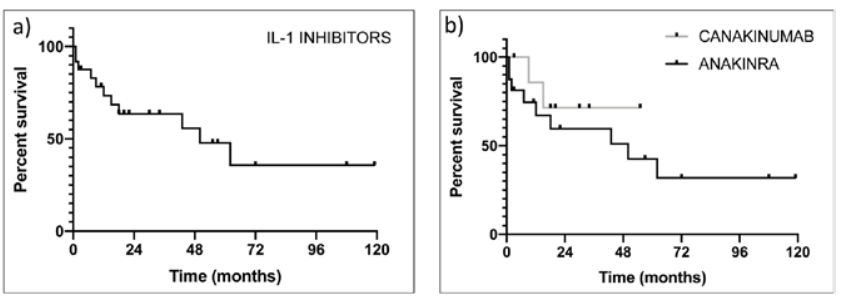

Figure 1. a) Retention rate of IL-1 inhibitors (24 courses); b) Retention rate of canakinumab ( 8 courses) and anakinra (16 courses).

Conclusion: In this multicentric cohort of patients affected by Schnitzler's syndrome, the treatment with IL- 1 inhibitors as $1^{\text {st }}, 2^{\text {nd }}$ or $3^{\text {rd }}$ line biological treatment permitted a good disease control and corticosteroid reduction in patients who did not respond to csDMARDs and/or to prior other biological DMARDs. The optimal dosage of these drugs needs to be tailored for every patient.

Acknowledgements: AIDA Network

Disclosure of Interests: Francesca Crisafulli: None declared, Antonio Vitale: None declared, Carla Gaggiano: None declared, Lorenzo Dagna: None declared, Giulio Cavalli Speakers bureau: SOBI, Novartis, Paid instructor for: SOBI, Novartis, Consultant of: SOBI, Novartis, Rolando Cimaz: None declared, Ombretta Viapiana: None declared, Florenzo lannone: None declared, Giuseppe Lopalco: None declared, Roberto Bortolotti: None declared, Masen Abdel Jaber: None declared, Carlomaurizio Montecucco: None declared, Sara Monti: None declared, Silvia Balduzzi: None declared, Giacomo Emmi: None declared, Paolo Airò: None declared, Franco Franceschini: None declared, Luca Cantarini Speakers bureau: SOBI, Novartis, Paid instructor for: SOBI, Grant/research support from: SOBI, Novartis, Micol Frassi: None declared

DOI: 10.1136/annrheumdis-2021-eular.3071

\section{OP0094 PULMONARY ARTERIAL HYPERTENSION IN ADULT- ONSET STILL'S DISEASE: A CASE SERIES OF 13 PATIENTS}

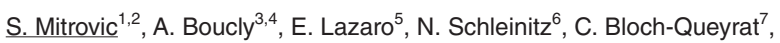
C. Christides ${ }^{8}$, J. Pouchot ${ }^{9}$, M. Humbert ${ }^{3,4,10}$, D. Montani ${ }^{3}$, L. Savale ${ }^{3}$, X. Jaïs ${ }^{3}$, O. Sitbon ${ }^{3,4}$, B. Fautrel ${ }^{11,12,13,14}$. ${ }^{1}$ Hôpital Pitié-Salpêtrière, AP-HP, Department of Rheumatology, Paris, France; ${ }^{2}$ Institut Mutualiste Montsouris, Department of Medicine, Paris, France; ${ }^{3} \mathrm{H}$ ôpital Bicêtre, AP-HP, Service de Pneumologie, Centre de Référence de l'Hypertension Pulmonaire, Paris, France; ${ }^{4}$ Université Paris-Sud, Université Paris-Saclay, INSERM Unité Mixte de Recherche en Santé S_999, Le Kremlin-Bicêtre, France; ${ }^{5} \mathrm{CHU}$ Bordeaux, Service de Médecine Interne et Maladies Infectieuses, Bordeaux, France; ${ }^{6}$ Hôpital Timone AP-HM, Service de Médecine Interne, Marseille, France; ${ }^{7}$ Hôpital Avicennes, Médecine Interne, Bobigny, France; ${ }^{8}$ Centre Hospitalier Henri Duffaut, Service de Médecine Interne, Avignon, France; ${ }^{9} \mathrm{Hôpital}$ Européen Georges Pompidou, AP-HP, Service de Médecine Interne, Paris, France; ${ }^{10}$ Université Paris-Sud, Université Paris-Saclay, Le Kremlin-Bicêtre, France; ${ }^{11}$ Hôpital Pitié-Salpêtrière, $A P$-HP, Service de Rhumatologie, Paris, France; ${ }^{12}$ Centre de Référence des Maladies Auto-Inflammatoires rares et des Amyloses, (CeRéMAIA), Paris, France; ${ }^{13}$ Pierre Louis Institute of Epidemiology and Public Health, INSERM UMR 1136, Paris, France; ${ }^{14}$ Sorbonne Université, Department of Rheumatology, Paris, France

Background: Pulmonary Arterial Hypertension (PAH) is a rare but potentially fatal complication of Adult-Onset Still's Disease (AOSD) (1). To date, only isolated observations have been published.

Objectives: To establish the largest case series of AOSD patients with $\mathrm{PAH}$, and to describe their clinical profile, evolution and response to treatments.

Methods: Cases were retrospectively identified from the French PAH network database and from an online call of the "Club Rhumatismes et Inflammation" (http://www.cri-net.com). To be included, all patients had to fulfil the Yamaguchi or Fautrel's criteria for AOSD and PAH had to be confirmed by right heart catheterization. The data were collected using a standardized questionnaire.

Results: Thirteen patients were identified. All were female, the mean age at PAH diagnosis was $32 \pm 12$ years, $2(15 \%)$ patients were Caucasian, $6(46 \%)$ from
Sub-Saharan Africa, 1 (8\%) from Asia and 4 (31\%) from West Indies. Only 2 (15\%) patients were smokers. All patients had a systemic onset of AOSD, 12 had a polycyclic and 1 a chronic articular evolution, and the mean delay between AOSD and PAH diagnosis was 2.9 (range $1.7-5.4$ ) years. At PAH diagnosis, patients were receiving the following treatments: $13(100 \%)$ corticosteroids (median dose $12 \mathrm{mg}$ [interquartile range (IQR) 9-18]), 3 (23\%) methotrexate, 8 $(61 \%)$ interleukin (IL)-1 inhibitors (exposure median duration 6.7 months [IQR 3.6-8.5]), none IL-6 inhibitors, 2 (15\%) TNF inhibitors. Six (46\%) patients developed PAH during an AOSD flare. PAH was severe at diagnosis: 2 (15\%), 7 (54\%) and $4(31 \%)$ patients were in NYHA functional class II, III and IV, respectively, with a median 6-minute walk distance of $289 \mathrm{~m}$ [IQR 0-448], a mean pulmonary arterial pressure of $41 \pm 12 \mathrm{mmHg}$, a mean pulmonary arterial occlusion pressure of $6 \pm 3 \mathrm{mmHg}$, a mean cardiac output of $3.9 \pm 1.2 \mathrm{~L} / \mathrm{min}$, a mean cardiac index of $2.5 \pm 0.9 \mathrm{~L} / \mathrm{min} / \mathrm{m}^{2}$ and a median pulmonary vascular resistance of 7 Wood Units [IQR 6-11]. The treatment prescribed after PAH diagnosis is detailed in the table. The median follow-up was 34 months [IQR 7-42]. Five patients (38.5\%) died. Figure 1 shows the overall survival. The haemodynamic response to $\mathrm{PAH}$ treatment seemed to be dissociated from the prognosis since several patients have died while their haemodynamic had improved or almost normalised.

Conclusion: PAH is a rare but potentially severe complication of AOSD, leading to death in $38.5 \%$ of our cases series. AOSD remission should be physicians' objective, since $\mathrm{PAH}$ seems to occur when the underlying disease is not controlled.

REFERENCES:

[1] Feist E, Mitrovic S, Fautrel B. Mechanisms, biomarkers and targets for adult-onset Still's disease. Nat Rev Rheumatol. 2018;1:603-618.

Table 1. Therapeutic management

\begin{tabular}{lc}
\hline Treatment & $\mathbf{n ~ ( \% )}$ \\
\hline Inotropic therapy & $5(38 \%)$ \\
HTAP treatment & $10(77 \%)$ \\
- OMonotherapy & 3 \\
- Olnitial oral dual combination therapy & 3 \\
- nDual combination therapy including intravenous (IV) prostacyclin & 1 \\
- uUpfront triple combination therapy including IV prostacyclin & 3 \\
High-dose corticosteroids & $9(69 \%)$ \\
Interleukin 1 inhibitors initiation & $2(15 \%)$ \\
Interleukin 6 inhibitors initiation & $5(38 \%)$ \\
\hline
\end{tabular}

Acknowledgements: The authors want to thank the Club Rhumatismes et Inflammation for the diffusion of the online call.

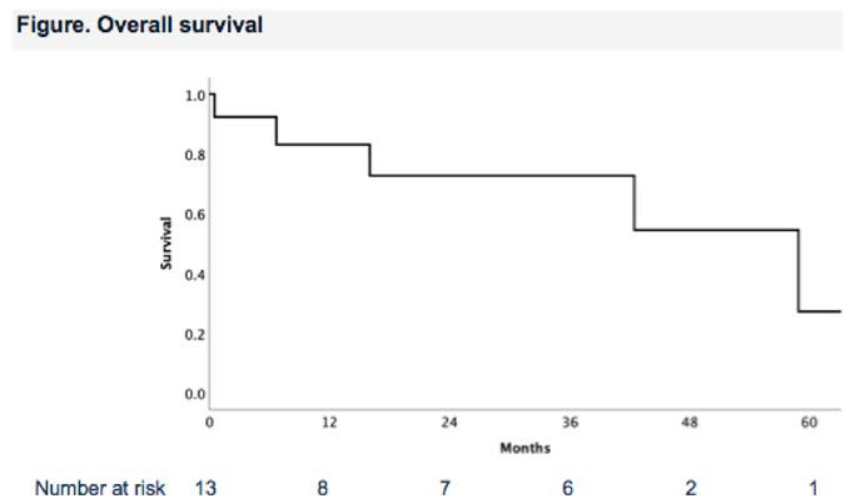

Disclosure of Interests: None declared DOI: 10.1136/annrheumdis-2021-eular.2668

\begin{tabular}{|l|l|}
\hline OP0095 & NON-GONOCOCCAL PYOGENIC ARTHRITIS OF \\
NATIVE JOINTS IN WESTERN AUSTRALIA. A \\
LONGITUDINAL POPULATION-BASED STUDY OF \\
FREQUENCY, RISK FACTORS AND OUTCOME.
\end{tabular}

J. Nossent ${ }^{1}$, W. Raymond ${ }^{1}$, D. Preen ${ }^{2}$, H. Keen ${ }^{1}$, C. Inderjeeth ${ }^{1} .{ }^{1}$ The University of Western Australia, Rheumatology, Crawley, Australia; ${ }^{2}$ The University of Western Australia, School of Population and Global Health, Crawley, Australia

Background: The worldwide incidence of PyA is reportedly rising due to a combination of increased longevity, multi- comorbidity, iatrogenic complications and increasing use of immunomodulating therapies, while there is limited data on longterm outcomes of PyA.

Objectives: To describe the recent incidence, risk factors and long-term outcomes in adults hospitalised with non-gonococcal pyogenic arthritis (PyA) of native joints in Western Australia (WA). 